\title{
Gestão dos resíduos da construção civil no litoral do Estado do Paraná
}

\section{Samuel Schmitz, Ednilson Viana*}

Universidade de São Paulo (USP). Escola de Artes, Ciências e Humanidades. Av. Arlindo Béttio, 1000. São Paulo-SP (CEP 03828-000).*E-mail: edn@usp.br.

Resumo. O objetivo do trabalho foi diagnosticar a geração e o manejo dos resíduos da construção civil (RCC) em dois municípios do litoral do Paraná. Além de pesquisa de literatura referente às características físico-territoriais e socioeconômicas, foram feitas entrevistas, mapeamentos, estimativa quantitativa e caracterização dos RCC através do monitoramento de empresas transportadoras. Os índices de geração obtidos foram de 327,4 kg.ano.hab ${ }^{-1}$, em Matinhos, e de 190,6 kg.ano.hab ${ }^{-1}$, em Pontal do Paraná, o que equivale a, respectivamente, $51,9 \%$ e $37,8 \%$ do total dos resíduos sólidos urbanos em cada município. A dinâmica de geração entre os dois municípios é diferenciada, apesar de semelhanças quanto à atividade turística. Além disso, o papel destes municípios tem se limitado apenas a ações corretivas pontuais, sem uma preocupação amplificada de gestão para estes resíduos no cenário econômico e ambiental em que se encontram. O cenário mostra que uma usina de reciclagem de RCC e de ecopontos no litoral do Paraná seria um passo importante para vencer as dificuldades de gestão destes resíduos em uma área isolada geograficamente de outras partes do Estado do Paraná.

Palavras-chave: Resíduos da construção, Gestão ambiental, Resíduos sólidos, Zona costeira.

\begin{abstract}
Management of construction waste on the coast of Paraná. The work objective was to detect the generation and management of waste for civil constrution in two coastal municipalities of Paraná. In addition to literature regarding of physical-territorial and socio-economic, interviews, mappings, quantitative estimation and characterization of CDW by monitoring carriers were held. The generation rates obtained were 327.4 kg.ano.hab ${ }^{-1}$, in Matinhos, and 190.6 kg.ano.hab ${ }^{-1}$, in Pontal do Paraná, which is equivalent, respectively, to $51.9 \%$ and $37.8 \%$ of total solid waste in each municipality. The dynamics of generation between the two cities is different despite similarities in tourism. Moreover the role of municipalities has been limited to specific corrective actions without a concern amplified for these waste management in economic and environmental setting in which they find themselves. The scenario shows that a CDW recycling plant on the coast of Paraná State would be an important step to overcome the difficulties of managing these wastes in a geographically isolated area from other parts of the Paraná State.
\end{abstract}

Keywords: Construction waste, Environmental management, Solid waste; Coastal zone.
Recebido: 20/10/2015

Aceito: 14/12/2015

Publicado: 31/12/2015

Acesso Aberto

Artigo completo

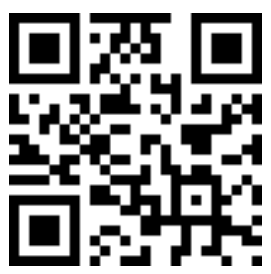




\section{Introdução}

Os resíduos da construção civil (RCC) são aqueles provenientes de construções, reformas, reparos e demolições ou os resultantes da preparação e da escavação de terrenos e constituídos por tijolos, blocos cerâmicos, concreto em geral, solos, rochas, metais, resinas, colas, tintas, madeiras e compensados, forros, argamassa, gesso, telhas, pavimento asfáltico, vidros, plásticos, tubulações, fiação elétrica, etc (Brasil, 2002).

De acordo com as suas características, os RCC são classificados em quatro classes (A, B, C e D), segundo a Resolução CONAMA n 348/2004 (Brasil, 2004), que altera a Resolução CONAMA ${ }^{\circ}$ 307/2002 (Brasil, 2002), onde esta inclui o amianto na classe de resíduos perigosos.

Os resíduos Classe A compreendem os resíduos reutilizáveis ou recicláveis como agregados tais como solos provenientes de terraplanagem, componentes cerâmicos, argamassa e peças de concreto. Os resíduos Classe B referemse aos resíduos recicláveis para outras destinações tais como: plásticos, papel, metais, vidros, madeiras e outros. Os resíduos Classe C são aqueles resíduos para os quais não foram desenvolvidas tecnologias ou aplicações economicamente viáveis que permitam a sua reciclagem/ recuperação, tais como os produtos oriundos do gesso. Os resíduos Classe D envolvem os resíduos perigosos oriundos do processo de construção tais como tintas, solventes, peças que contenham amianto, óleos e outros ou aqueles contaminados oriundos de demolições, reformas e reparos de clínicas radiológicas, instalações industriais, dentre outros.

As Resoluções CONAMA $n^{\circ}$ 431/2011 e 448/2012 alteraram a resolução CONAMA n ${ }^{\circ}$ 307/2002 (Brasil, 2002, 2011, 2012) em diversos aspectos que merecem atenção.

A Resolução do CONAMA $n^{\circ}$ 431/2011 alterou o artigo $3^{\circ}$ da Resolução CONAMA n ${ }^{\circ} 307 / 2002$, mudando o gesso de classe, onde este passou a não ser mais considerado como classe $\mathrm{C}$ e sim como classe B, ou seja, considerado como resíduos recicláveis para outras destinações.

A Resolução CONAMA $\mathrm{N}^{\circ}$ $448 / 2012$, por sua vez, alterou os artigos $2^{\circ}$,

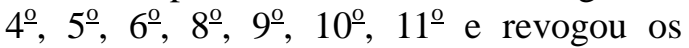
artigos $7^{\circ}, 12^{\underline{0}}$ e $13^{\circ}$. As alterações nos referidos artigos referiram-se a uma nova redação de vários destes artigos, a redefinição de alguns conceitos e o acréscimo de outros elementos importantes na gestão dos RCC.

Com relação às redefinições conceituais, estas referiram-se aos aterros de resíduos classe A, área de transbordo e triagem de RCC e resíduos volumosos, gerenciamento de resíduos sólidos e gestão integrada. Os principais acréscimos foram realizados nos artigos $4^{\circ}$ e $5^{\circ}$, onde $o$ artigo $4^{0}$ inclui o tratamento dos resíduos sólidos e a disposição ambientalmente adequada dos rejeitos como elemento da gestão dos RCC. $\mathrm{O}$ artigo $5^{0}$ estabelece que os Planos de Gestão de RCC nas suas diversas esferas de abrangência devem ser elaborados em conformidade com os Planos Municipais de Gestão Integrada de Resíduos Sólidos.

A geração de RCC no Brasil, segundo o panorama dos resíduos sólidos realizado pela Abrelpe (2014), é estimada em 0,603 kg/hab.ano e segundo estudos de Pinto (2005) para 11 municípios da região sudeste, os RCCs correspondem a $61 \%$ dos resíduos sólidos urbanos. Além disso, a geração dos resíduos da construção ocorre de forma difusa e se concentra na sua maior parcela no pequeno gerador, ou seja, cerca de $70 \%$ do resíduo gerado, provenientes de reformas e pequenas obras (Sinduscom, 2012). Os impactos da má gestão destes resíduos podem contribuir para a redução da qualidade de vida urbana e ainda sobrecarrega os serviços municipais de limpeza pública (Schneider e Philippi Jr., 2004), especialmente quando há ausência de planos de gestão e políticas públicas na área (Pinto e González, 2005).

Estes aspectos quando considerados em uma região litorânea como a do Paraná, podem ser ainda mais graves, onde grande parte do espaço constituem áreas de proteção ambiental como florestas, banhados, mangues e restingas e ainda pelo fato de que o pequeno gerador é um das 
fontes mais difíceis de serem controladas e fiscalizadas. A proximidade do verão, por exemplo, culmina com o aumento no número de reformas devido as condições de umidade local e maresia, provocando um aumento na quantidade de RCC gerados e um aumento do descarte indadequado em áreas impróprias para esta finalidade.

Os municípios de Pontal do Paraná e Matinhos, que fazem parte do litoral do Paraná, apresentam muitos pontos de descarte irregular de RCC e uma produção destes resíduos ainda desconhecida do ponto de vista do planejamento. Deste modo, realizar um diagóstico dos RCC é um passo importante para se conhecer a realidade local de geração e descarte destes resíduos e contribuir para um planejamento futuro de ações corretivas, a serem contempladas no Plano de Gestão de Resíduos Sólidos dos referidos municípios. Esse diagnóstico leva em conta as peculiaridades do ambiente litorâneo e poderá auxiliar no desenvolvimento de programas e instrumentos municipais que busquem mudar esta realidade local, evitando futuras implicações ambientais e econômicas para estes municípios.

\section{Material e métodos}

Para atingir os objetivos descritos, esta pesquisa apoiou-se em quatro etapas, conforme metodologia adaptada de Marques Neto (2005), e considerando a realidade local dos municípios em estudo:

1) Levantamento das características naturais, de desenvolvimento urbano e socioeconômicas de Matinhos e Pontal do Paraná. O objetivo deste levantamento foi auxiliar a compreensão da relação entre ambiente, ocupação urbana e a gestão dos RCC nos referidos municípios. A obtenção de dados nesta etapa foi através de levantamento bibliográfico.

2) Caracterização dos agentes envolvidos no manejo dos RCC. Aqui foram identificados os agentes envolvidos no processo de manejo dos RCC e aplicados questionários por meio de entrevistas, para a obtenção de dados sobre a geração, coleta, transporte, triagem e destino final dos RCC.

3) Mapeamento dos locais de deposição, armazenamento e bota-fora de RCC. Este mapeamento teve como base as informações coletadas junto às entrevistas com os agentes envolvidos no manejo dos RCC, assim como por meio de saídas de campo realizadas ao longo da periferia dos municípios estudados. Os bota-foras regulares e irregulares e locais de armazenamento encontrados tiveram as coordenadas geográficas registradas com auxílio de um GPS, além do registro da situação desses locais através de imagens fotográficas e anotações pertinentes.

Considerando a dificuldade de medir a quantidade de RCC descartado nos bota-foras, buscou-se estimar visualmente 0 volume aproximado destes de acordo com as suas dimensões e formatos, relacionando-os com formas geométricas conhecidas. Os materiais prevalecentes foram registrados de acordo com as observações in loco. Com isso, foi possível o mapeamento para identificação das áreas mais sujeitas a este tipo de depósito.

4) Estimativa quantitativa dos RCC gerados. Esses dados foram obtidos a partir de duas fontes distintas:

a) Áreas licenciadas para construção e demolição: Através das áreas licenciadas de demolição e de novas construções foi feita uma estimativa da geração dos RCC em ambos os municípios utilizando-se os valores-padrão de geração de RCC por metro quadrado construído e demolido, presentes na literatura.

b) Monitoramento por fichas controle: Este monitoramento consistiu na estimativa da geração de RCC a partir da ação dos agentes transportadores, realizada através do preenchimento de uma ficha controle cadastral para cada carga transportada. O preenchimento das fichas iniciou-se no dia 26/7/2010 e seguiu ininterruptamente até o dia 31/01/2011. As informações coletadas junto aos transportadores referem-se às características da obra que gerou o material, composição, volume, local de recolhimento e ainda indicação de possível reutilização ou processamento. Esse monitoramento 
contribuiu com a parcela das reformas no cálculo da massa total de RCC gerados.

\section{Resultados e discussão}

\section{Caracterização ambiental de Matinhos e Pontal do Paraná}

Os Municípios de Pontal do Paraná e Matinhos apresentam, $10,5 \%$ e $27,4 \%$ de sua área coberta por Unidades de Conservação (UC), respectivamente (Pierri et al., 2006). Com características principalmente litorâneas, esses municípios possuem um perfil fitoecológico caracterizado principalmente pela Floresta Pluvial Sub-Tropical Atlântica, formações vegetais pioneiras de influência marinha (Restinga) e formações vegetais pioneiras de influência fluviomarinha (manguezais) (Angulo, 1999; Bigarella, 2009).

As características dos solos predominantes nesses municípios, sejam aquelas de permanente influência da superficialidade do lençol freático (várzeas, caxetais e mesmo florestas encharcadas) como aquelas de solos arenosos (dunas, florestas de restinga e de taboleiro), são altamente restritivas aos padrões tradicionais de utilização humana (como a agropecuária e a urbanização). Essa visão, de consenso nos meios técnico e científico, é respaldada pela legislação ambiental, sensível aos problemas que podem advir de sua ocupação não criteriosa e desordenada. Entretanto, o que se observa é a tendência nas últimas décadas do progressivo avanço da urbanização pela paisagem (Angulo, 1999).

\section{Histórico do desenvolvimento urbano e socioeconomia de Matinhos e Pontal do Paraná}

No geral, o histórico do desenvolvimento urbano de Matinhos e Pontal do Paraná esteve ligado às obras de infraestrutura viárias, as quais incentivaram a atividade do turismo de veraneio, impulsionando a urbanização dos mesmos. Assim, a ocupação do território tornou-se mais intensa a partir da década de 1950, com o melhoramento da rodovia rodovia PR-407, que promove a integração da rodovia BR-277, que liga Curitiba à
Paranaguá e à Pontal do Paraná. Esse fator, aliado ao aumento do interesse turístico pela região e crescimento do poder aquisitivo dos paranaenses, principalmente da classe média, acarretou uma rápida ocupação territorial. Cabe destacar que a ocupação foi acelerada pelo processo de especulação imobiliária (Pierri et al., 2006), tornando o esforço público para gestão de resíduos incompatível com a realidade da ocupação litorânea.

De acordo com COLIT (2006), que utilizou imagens de satélite de vários períodos para analisar a expansão da ocupação urbana no Município de Matinhos, a malha alterou-se significativamente nas últimas décadas, registrando o seu maior crescimento no período de 1980 a 2000. No mesmo período, em Pontal do Paraná, observou-se um crescimento acentuado da área urbana (Angulo, 1999). Assim, a expansão urbana vai pressionando cada vez mais as áreas com importância ambiental na região, inclusive pelo descarte irregular de RCC que vai se acumulando nas margens de rios, mangues e floresta.

Apesar de não existirem estudos que apontem as taxas de crescimento da mancha urbana na primeira década do século atual nos municípios pesquisados, é provável que o processo continue acelerado devido à atual estabilidade econômica pelo qual o Paraná e o Brasil vêm passando, o que fortalece o setor da construção local, uma vez que este é impulsionado pela aquisição de residências de veraneio. Contudo, é sensível a diminuição das taxas anuais de crescimento populacional entre os períodos de 1991/2000 e 2000/2010 (Tabela 1 ), o que pode estar indicando diminuição nas taxas de migração para o litoral que estiveram entre as maiores do estado na década de 1990 (Deschamps, 2002).

Em geral, grande parte dos imigrantes que chegam ao litoral é pobre e com baixo nível de instrução, buscando oportunidades ligadas principalmente ao setor de serviços, como a construção civil. Este baixo nível de instrução pode ser um indicador da qualidade dos serviços na região, fator importante para a geração de RCC no litoral do Paraná, uma vez que 
Tabela 1. População e grau de urbanização/taxas anuais de crescimento populacional dos municípios em estudo para o período de 1970 e 2010.

\begin{tabular}{|c|c|c|c|c|c|c|c|c|c|c|}
\hline Municípios $\downarrow$ & \multicolumn{5}{|c|}{ População } & \multicolumn{5}{c|}{ Taxas anuais de crescimento } \\
\hline Ano/Período $\rightarrow$ & 1970 & 1980 & 1991 & 2000 & 2010 & $1970 / 80$ & $1980 / 91$ & $1991 / 00$ & $00 / 2010$ & $1970 / 2010$ \\
\hline Matinhos & 4.317 & 5.672 & 11.325 & 24.184 & 29.172 & 2,77 & 6,49 & 8,7 & 1,89 & 4,89 \\
Taxa urbanização & 73 & 85 & 96 & 99 & - & - & - & - & - & - \\
\hline Pontal do Paraná & - & - & $(*) 5.577$ & 14.323 & 20.839 & - & - & 10,93 & 3,82 & - \\
Taxa urbanização & - & - & 97 & 99 & - & - & - & - & - & - \\
\hline
\end{tabular}

Fonte: IBGE - Censos Demográficos 1970-2010. Modificado de Pierri (2003). (*) Reconstituída em base de dados de setores censitários do Censo 1991.

pode estar relacionado com maior desperdício na execução de obras.

Em Matinhos e Pontal do Paraná o setor terciário predomina na economia e está voltado principalmente às atividades relacionadas ao turismo de veraneio. Entretanto, já há indicativos de alterações nesse perfil à medida que se acentua uma dinâmica local que extrapola a sua característica de ocupação flutuante, reforçando a ocupação permanente (Deschamps e Kleinke, 2000). Neste contexto, a participação da construção civil representa aproximadamente $70 \%$ em Pontal do Paraná (MMA, 2004b) e Matinhos (Colit, 2006).

Matinhos e Pontal do Paraná apresentam uma mancha urbana em forma de corredor que margeia a costa oceânica entre as baías de Guaratuba ao sul e de Paranaguá ao norte. Em Pontal do Paraná, a malha urbana presente compreende desde fragmentos de instalações industriais/portuárias, urbanização convencional normal e informal em estágio predominantemente horizontal, incluindo loteamentos de residências de veraneio, e também fragmentos de zonas de proteção ambiental (MMA, 2004b). Cerca de 1/3 de suas ocupações são irregulares (Colit, 2006). Já em Matinhos, cerca de 30\% dos balneários estão com a ocupação consolidada e apresentam tendência vertical (Praia Mansa, Praia Brava e Praia Central) e os demais em estágio de consolidação, com inúmeros terrenos próximos ao mar ainda não ocupados (MMA, 2004a). Esse município não possui estimativa quanto ao percentual de ocupações irregulares (Colit, 2006).
Entretanto, mesmo possuindo uma legislação de zoneamento, através do Decreto Estadual no 2.722/1984 (Paraná, 1984), a urbanização desses municípios tem se caracterizado pela ocupação junto à linha de costa ou mesmo sobre a praia, pela destruição das dunas, pelo aterro de brejos e pela descaracterização de rios e córregos. Ou seja, pela desconsideração da morfologia e, sobretudo, da dinâmica dos ambientes costeiros (Pierri et al., 2006).

Por último, a anunciada instalação de terminais portuários em Pontal do Paraná, cuja licença ambiental já está aprovada, contudo condicionada a aprovação de uma nova estrada de acesso, muito provavelmente irá ocorrer em um futuro próximo e criará uma confluência local inédita das atividades portuária e turística, cuja compatibilidade será um grande desafio. Mas, independentemente de como isso transite, pode-se afirmar que esse elemento iniciará, sem dúvida, uma nova fase na configuração espacial e econômica do litoral (Pierri et al., 2006).

\section{Caracterização dos agentes envolvidos na geração, transporte e manejo dos RCC}

São considerados aqui como geradores não somente as construtoras, empresas de terraplanagem, empresas transportadoras mas também as prefeituras, que no caso desta última, também cabe a tarefa de dar um destino aos RCC que foram descartados clandestinamente pela população na área do município.

As prefeituras estudadas neste trabalho não dispõem de um programa municipal de gerenciamento para os RCC, 
caracterizando-se por ações corretivas de manejo, através do recolhimento de deposições irregulares. Essas deposições foram relatadas pela prefeitura como sendo o principal problema que elas vêm enfrentando quanto à gestão destes resíduos. Contudo, mesmo possuindo legislação municipal referente à proibição da disposição inadequada de RSU (Resíduos Sólidos Urbanos), através do Decreto Municipal $n^{\circ}$ 381/2006 (Matinhos, 2006) e Lei Complementar $\mathrm{n}^{\circ}$ 004/2007 (Pontal do Paraná, 2007), em Matinhos e Pontal do Paraná, respectivamente, não há fiscalização referente às deposições irregulares de RCC.

A coleta de RCC pelas prefeituras em locais irregulares é feita utilizando-se caminhões, máquinas carregadeiras e pessoal de mão de obra. Não há estimativa do valor gasto nem do montante total recolhido de RCC destas deposições. A destinação final desses resíduos, efetuada por ambas as prefeituras, em sua grande maioria, é o uso como aterro na abertura de novas ruas ou ainda na sustentação de encostas de canais e córregos. Quando a carga recolhida apresenta uma quantidade considerável de outros resíduos que prejudicam este modo de deposição, como resíduos doméstico, móveis e eletrodomésticos, entre outros, que comumente são dispostos de forma irregular juntamente com os RCC, o material é encaminhado ao aterro sanitário.

$\mathrm{O}$ aterro sanitário que serve aos dois municípios é resultado de um consórcio entre ambos, denominado de Consórcio Intermunicipal para Aterro Sanitário (CIAS), localizado em Pontal do Paraná. Em geral, é proibido o descarte de RCC em aterro sanitário. Contudo, o CIAS possui autorização do Instituto Ambiental do Paraná (IAP) para o recebimento controlado de RCC, com a justificativa de que esses resíduos são importantes para a manutenção das vias de acesso utilizadas pelos caminhões dentro do aterro.

Em Matinhos, foi desativado no final de 2010 um bota-fora privado e autorizado para o recebimento de resíduos vegetais, sem controle algum e com deposições de resíduos domésticos, móveis, além de RCC em geral, facilmente detec- tadas por observação in loco. No início de 2011 foi autorizado o funcionamento de um novo bota-fora vegetal no município.

As construtoras nos dois municípios atuam em construções e reformas. Elas não recebem fiscalização sobre o manejo e destinação dos RCC produzidos, mas por outro lado existe uma preocupação quanto à separação dos resíduos e a sua reutilização sempre que isso represente vantagem econômica. Em geral, essas construtoras contratam as empresas transportadoras para a destinação dos RCC produzidos.

As empresas transportadoras de RCC funcionam através da locação de caçambas estacionárias pelos geradores. Normalmente elas recolhem pouco material vegetal, sendo mais utilizadas para a coleta dos resíduos gerados por obras de reformas e construções diversas, caracterizadas pela geração do chamado "entulho" de obra, como caliça e madeiras. No geral as empresas transportadoras realizam ou permitem a terceiros (carrinheiros) a triagem do material, retirando madeiras, plásticos, metais, papeis ou qualquer material que tenha uma utilidade ou valor, para encaminhá-los para a reciclagem ou reutilização. O restante do material, que compreende a maior parte do resíduo, é normalmente destinado como aterro para terceiros.

As empresas de terraplanagem em Matinhos e Pontal do Paraná realizam limpezas de terrenos, aterramentos, escavações e demolições. Normalmente o resíduo recolhido é encaminhado para ser utilizado como aterro, tanto para terceiros que compram o material, como em locais próximos aos de geração, como ruas e terrenos baldios. Em Matinhos, parte desse material (com exceção daquele de origem de demolição) é encaminhada ao bota-fora autorizado. Quanto às demolições, apesar de não existir planejamento ou treinamento nessa área (para o maior aproveitamento dos materiais), são reaproveitados alguns materiais como caixas de água, janelas, portas, madeiras e recicláveis. O restante do material é destinado como aterro. 


\section{Mapeamento dos locais de deposição, armazenamento e bota-fora de RCC}

Através das entrevistas realizadas com os agentes envolvidos no manejo dos RCC, somado com percursos efetuados nas periferias de ambos os municípios, entre os dias 23/12/2010 e 15/01/2011, foi possível mapear os locais de armazenamento de RCC, assim como os locais utilizados como bota-fora ilegais, aqui definidos como deposições acima de $5 \mathrm{~m}^{3}$. As pequenas deposições irregulares não foram mapeadas, uma vez que estas são continuamente removidas pelas municipalidades. Contudo, durante as saídas de campo estas deposições foram facilmente observadas em ambos os municípios, o que remete ao descomprometimento, em geral, da população, da indústria da construção civil e gestores públicos locais quanto ao manejo responsável desses resíduos.

Em Pontal do Paraná foram mapeados 16 bota-fora irregulares, estimados em $378 \mathrm{~m}^{3}$. Os materiais prevalecentes foram os vegetais, seguidos de caliça e madeiras. O lixo doméstico e móveis velhos mostraram-se como os principais materiais acompanhantes. A localização destes esteve associada aos três principais balneários do município (Pontal do Sul, Shangri-lá e Praia de Leste). Na Região do Balneário Atami (entre Pontal do Sul e Shangri-la), apesar de possuir uma intensa atividade de construção civil, não foi encontrado nenhum bota-fora, uma vez que, por ser uma região onde o padrão das construções é elevado, também é a região de maior demanda por serviços de transporte de RCC.

Em Matinhos, foram mapeados seis bota-fora irregulares, com um total estimado de $226 \mathrm{~m}^{3}$. Os materiais prevalecentes foram a caliça, seguida de vegetais. $\mathrm{O}$ menor volume total, assim como a menor representatividade dos resíduos vegetais em relação a Pontal do Paraná, provavelmente esteja relacionado com a existência do bota-fora autorizado para esses materiais. Da mesma forma que em Pontal do Paraná, o lixo doméstico e móveis velhos mostraram-se como os principais materiais acompanhantes, colaborando com a afirmação de que as deposições irregulares de entulho de RCC atraem o descarte de outros resíduos.

Está sendo instalada uma central de triagem de resíduos sólidos urbanos, inclusive de RCC, em Matinhos, para encaminhamento à reutilização ou reciclagem dos mesmos, projeto este de iniciativa privada, estimado em cinco milhões de reais, o que certamente irá trazer benefícios socioeconômicos e ambientais tanto para Matinhos como para Pontal do Paraná, que também está incluso no projeto. Entretanto, não existe muita informação sobre como se dará o processamento dos RCC no mesmo.

A existência de áreas de deposições irregulares é um aspecto intrínseco da gestão corretiva exercida pelas municipalidades, dada a falta de soluções para o descarte dos RCC. Esses resíduos depositados de forma irregular são considerados um problema de limpeza publica, acarretando uma série de inconvenientes para toda a sociedade como elevação dos custos para o sistema de limpeza urbana e saúde publica, enchentes, assoreamento e contaminação de cursos d'água, contaminação de solo, obstrução de sistemas de drenagem, etc. Estes fatores contribuem para impactar negativamente ambiente e paisagem o que pode prejudicar o turismo na região e consequentemente a economia local.

Segundo Morais (2006), a disposição ilegal em locais inadequados, tais como ruas, calçadas, terrenos baldios, encostas, leitos de córregos e rios e áreas de preservação ambiental, constituem-se nas principais causas dos impactos que estes causam ao meio ambiente. Deposições e bota-foras irregulares foram facilmente observados em todas essas localizações durante a pesquisa.

Os RCC dispostos inadequadamente poluem o solo, degradam paisagens e constituem uma séria ameaça à saúde pública. O acumulo de RCC em local inadequado atrai resíduos não inertes, oferecendo, simultaneamente, água, alimento e abrigo para muitas espécies de vetores patogênicos como ratos, baratas, moscas, vermes, bactérias, fungos e vírus (Schneider, 2003). 


\section{Caracterização quantitativa}

Para o município de Matinhos o levantamento dos alvarás de construção do ano de 2001 até novembro de 2010, exceto o caderno do ano de 2009 que não esteve disponível, mostrou que no referido período foram licenciados $293.442 \mathrm{~m}^{2}$ de novas obras residenciais, comerciais, comerciais/ residenciais e públicas. Os registros mostraram um amplo domínio da categoria residencial das licenças, com $89 \%$ do total.

Para Pontal do Paraná, a prefeitura forneceu o levantamento de todos os alvarás de construção e licenças de demolição expedidos do ano 2000 até abril de 2010. Contudo, as regularizações imobiliárias efetuadas no mesmo período também estão categorizadas como alvarás de construção junto ao sistema municipal. Devido a isso, foram contabilizados apenas os valores relativos ao ano 2000 e de 2005 até abril de 2010, pois do ano 2001 até 2004 os registros de alvarás estão fortemente influenciados pelos processos de regularização imobiliária facilitados pela prefeitura, através da Lei Municipal no 303/2002 (Pontal do Paraná, 2002). Neste período, foram licenciados $240.366 \mathrm{~m}^{2}$ de obras residenciais, comerciais, comerciais/residenciais e públicas, sendo que a grande maioria referente à categoria residencial (92\%).

Segundo Souza et al. (2004), o valor-padrão que fornece a massa média de RCC gerados a partir de novas construções é igual a 49,58 kg.ano.hab ${ }^{-1}$ construído. Com isso pode-se calcular a massa média de RCC gerados em Matinhos a partir de novas construções, cujo valor é igual a 136 t mensais (considerando um mês de 26 dias, uma vez que se desconsideram os quatro domingos do mês) ou 5,2 t diárias. Da mesma maneira em Pontal do Paraná a média de RCC gerados por novas construções foi igual a $157 \mathrm{t}$ mensais (mês com 26 dias) ou 6 t diárias.

Segundo Pinto (1999), a massa estimada para as edificações executadas predominantemente por processos convencionais é igual a 1.200 kg.ano.hab ${ }^{-1}$. Esse valor foi adotado como padrão para as áreas licenciadas para demolição. Em 76 meses de registro foram licenciados para demolição 2.149,29 $\mathrm{m}^{2}$ em Pontal do Paraná, que multiplicados pelo valor-padrão somam 2.579 t, o que reflete uma média de $34 \mathrm{t}$ mensais (mês com 26 dias) ou 1,3 t diárias. Somando a massa média dos resíduos gerados por novas edificações e demolições, chega-se ao montante de 191 t.mês ${ }^{-1}$.

Com relação ao monitoramento por fichas controle em Pontal do Paraná, cinco empresas participaram desse processo, abrangendo a totalidade das empresas de locação de caçambas estacionárias (caminhão poliguindaste) e as principais que realizam limpeza de terrenos (caminhão basculante). Em Matinhos, foi monitorada por uma semana a empresa a qual concentra a totalidade do serviço de locação de caçambas no município.

Nota-se pela Tabela 2 que a dinâmica de geração de RCC é diferente nos dois municípios, embora sejam vizinhos e com característica de balneabilidade. Em Matinhos, a maior geração de RCC ocorreu no mês de dezembro, que precede a temporada de verão. Em Pontal do Paraná a maior geração ocorre em outubro. O Município de Matinhos, como era esperado, produz muito mais RCC que o Município de Pontal do Paraná, em virtude da maior população, tanto fixa quanto flutuante.

Cabe ressaltar que maioria das cargas de RCC monitoradas pertenceu à classe $\mathrm{A}$, segundo a resolução CONAMA $n^{\circ}$ 348/2004.

A densidade padrão do entulho foi adotada como equivalente a 1,39 t. $\mathrm{m}^{3^{-1}}$, conforme determinada por Zordan (1997). Para o cálculo da taxa de geração considerou-se o método proposto por Pinto e González (2005). Em Matinhos, a média mensal de RCC gerado por novas construções (obtida através do parâmetro das áreas licenciadas para novas construções) e reformas (obtida através do monitoramento das empresas coletoras) foi respectivamente 136 t e 660 t, as quais totalizam 796 t.mês ${ }^{-1}$. Do mesmo modo, em Pontal do Paraná foram calculadas $157 \mathrm{t}$ para as áreas licenciadas para novas construções e $34 \mathrm{t}$ 
Tabela 2. Volumes totais e de reformas e $\mathrm{n}^{\circ}$ de cargas totais de RCC transportados por mês por empresas privadas, de julho de 2010 a janeiro de 2011, em Matinhos e Pontal do Paraná.

\begin{tabular}{|c|c|c|c|c|c|c|}
\hline \multirow[b]{2}{*}{ Mês } & \multicolumn{3}{|c|}{ Matinhos } & \multicolumn{3}{|c|}{ Pontal do Paraná } \\
\hline & Reforma $\left(\mathrm{m}^{3}\right)$ & Total (m³) & $\mathbf{N}^{\circ}$ cargas & Reforma $\left(\mathrm{m}^{3}\right)$ & Total (m³) & Nocargas \\
\hline Julho* & 121 & 169 & 37 & 12 & 112 & 12 \\
\hline Agosto & 412 & 475 & 100 & 52 & 505 & 52 \\
\hline Setembro & 527 & 655 & 140 & 144 & 532 & 76 \\
\hline Outubro & 277 & 368 & 79 & 236 & 452 & 83 \\
\hline Novembro & 463 & 547 & 114 & 68 & 366 & 89 \\
\hline Dezembro & 655 & 762 & 157 & 40 & 92 & 22 \\
\hline Janeiro & 505 & 656 & 135 & 122 & 516 & 74 \\
\hline Total & 2.960 & 3.632 & 762 & 674 & 2.575 & 408 \\
\hline
\end{tabular}

*Dados da última semana de julho.

para demolições e, ainda, $140 \mathrm{t}$ para os resíduos transportados com origem em reformas, totalizando 331 t.mês ${ }^{-1}$

Nota-se pelos dados acima que o município de Pontal do Paraná concentra a maior produção de resíduos de novas construções e que o Município de Matinhos concentra a maior produção de resíduos de reforma, mostrando a dinâmica diferenciada de ambos os municípios e logicamente a composição dos RCC, influenciada pelo tipo de fonte geradora.

Com base nos dados mensais de produção de RCC de novas construções e reformas, a média anual por habitante em cada município foi de 327,4 kg.ano.hab ${ }^{-1}$ em Matinhos e 190,6 kg.ano.hab ${ }^{-1}$ em Pontal do Paraná. Isto mostra uma discrepância entre os dois municipios, provavelmente influenciada pelo padrão das construções e pelo tipo de geração ali presente, ou seja, de novas construções ou de reformas.

De 2002 até 2007, Pontal do Paraná depositou no aterro sanitário uma quantidade média de resíduos sólidos urbanos de 6.510 t.ano $^{-1}$ e Matinhos 8.835 t.ano ${ }^{-1}$ (Pontal do Paraná, 2008). Assim, é possível afirmar que a quantidade de RCC estimada em Matinhos e Pontal do Paraná é respectivamente equivalente a pelo menos $51,9 \%$ e $37,8 \%$ do total dos resíduos sólidos urbanos gerados em cada município. Cabe ressaltar que esses valores podem ser ainda mais significativos devido a não contabilização dos resíduos gerados por reformas transportados por ambas as prefeituras, e em Matinhos das áreas licenciadas para demolição e ainda dos RCC oriundos da limpeza de terrenos. No Brasil, os RCC representam cerca de $40 \%$ a $70 \%$ do total de resíduos sólidos urbanos em cidades de médio e grande porte (Pinto, 1999). Esse elevado percentual encontrado da participação dos RCC no total dos RSU gerados no âmbito dos municípios estudados é preocupante, visto a inexistência de planos de gerenciamento, o que acarreta a proliferação de disposições e bota-foras clandestinos, além da diminuição da vida útil do aterro sanitário (CIAS), em um local onde inexistem áreas adequadas para novos aterros sanitários.

Um caminho muito benéfico para os municípios estudados seria a criação de ecopontos para facilitar o recebimento dos RCC pela população local e de uma usina de reciclagem de RCC para atender os 7 municípios do litoral do Paraná (Matinhos, Pontal do Paraná, Paranaguá, Antonina, Guaraqueçaba, Guaratuba e Morretes), considerando que o município de Paranaguá é vizinho aos dois municípios estudados e tem ali o porto de Paranaguá, também como uma importante fonte de geração de RCC.

Uma usina de reciclagem de RCC agrega valor ao produto final e por isso poderá permitir o uso local/regional destes resíduos, podendo ir além do litoral do Paraná. O isolamento geográfico natural em relação ao continente e imposto pela serra, fortalece ações no sentido de valorização destes resíduos e representado por uma usina de reciclagem de RCC regional. 
A redução na fonte geradora é uma questão primordial quando se trata de RCC e considerando o pequeno gerador, seria importante a realização de campanhas intensas pelos municípios para orientar os moradores sobre a importância do descarte correto dos RCC produzidos e dos riscos ambientais e à saúde pública que podem ser provocados por estes.

Os ecopontos, citados acima, aproximam o pequeno gerador das vias de escoamento e por isso são considerados aqui como um importante instrumento na gestão dos RCC nestas localidades. A distribuição destes ecopontos no espaço urbano pode ampliar o alcance da coleta destes resíduos e o aproveitamento destes para uma gestão mais justa dos RCC, para um modo de vida mais sustentável.

\section{Conclusões}

As características naturais dos municípios estudados são altamente restritivas à ocupação urbana, contudo o que se observa é o contínuo avanço da malha urbana sobre a paisagem, principalmente a partir da década de 1980. Esses municípios são predominantemente urbanos, com as suas economias voltadas ao setor terciário, as quais, impulsionadas pela indústria do turismo, possuem a construção civil como seu principal pilar e, portanto, uma grande geradora de RCC.

As deposições e bota-foras irregulares de RCC são formas comuns de destino final praticadas nos municípios estudados, o que representa um impacto negativo ao ambiente em potencial, seja pelo potencial de contaminação do solo e água, seja pelo risco à saúde pública, como, inclusive, a degradação da paisagem, a qual é fundamental para a atividade turística local. Contudo, as prefeituras não possuem um plano integrado para a gestão desses resíduos, exercendo apenas ações corretivas de manejo através do recolhimento das deposições irregulares. Porém, falta comprometimento com a correta utilização e beneficiamento desses resíduos, os quais são utilizados principalmente como aterro ou material fixador de encostas de canais, sem que passem por qualquer processo de triagem ou processamento, e ainda, uma parcela é encaminhada ao aterro sanitário, comprometendo a vida útil do mesmo.

Os RCC representam uma parcela significativa dos RSU dos municípios estudados, sendo 51,9\% em Matinhos e 37,8\% em Pontal do Paraná, o que significa um índice per capita provável de 327,4 kg.ano.hab ${ }^{-1}$ e 190,6 kg.ano.hab ${ }^{-1}$, respectivamente. As fontes geradoras nos dois municípios também são diferenciadas, mesmo eles tendo características semelhantes, pois enquanto Pontal do Paraná gera mais RCC com origem em novas construções, Matinhos gera mais RCC com origem em reformas. Este fato influencia inclusive a composição dos RCC em ambos os municípios.

Em geral, o destino final dos RCC, praticado pelas empresas que transportam RCC nos municípios estudados, tem sido a sua utilização como material para aterro de terrenos particulares. Todavia, em muitos casos, tais terrenos são áreas baixas alagadas, com a presença de vegetação de banhados, o que pode facilitar a contaminação do lençol freático, além de inviabilizar a utilização do material em processos mais nobres, como a produção de artefatos de concreto e argamassas, visto que a maioria dos RCC transportados, de acordo com a Resolução CONAMA $n^{\circ}$ 348/2004 (Brasil, 2004), é pertencente à classe "A".

Dessa forma, percebe-se que o atual cenário da geração e gestão dos RCC em Pontal do Paraná e Matinhos não apresenta os mecanismos de gestão preconizado pela legislação no âmbito federal, seja pela Resolução CONAMA no 307/2002 (Brasil, 2002), seja pela atual Política Nacional de Resíduos Sólidos, instituída pela Lei $\mathrm{n}^{\mathrm{o}}$ 12.305/2010 (Brasil, 2010). Portanto, medidas que visem à elaboração e aplicação de Programas Municipais de Gerenciamento dos RCC são de suma importância em termos ambientais e econômicos para os municípios estudados, uma vez que podem contribuir para a preservação não apenas da paisagem, mas também do ambiente costeiro, fundamentais para a atividade turística local, assim como 
incentivar práticas de gerenciamento como a reciclagem.

Sugere-se então a criação de uma Usina de Reciclagem de Resíduos da Construção Civil para os sete municípios do litoral do Paraná como um forte instrumento de gestão destes resíduos, tendo em vista a situação que pode ser recorrente de produção e descarte de RCCs em todos eles e a barreira geográfica que é a serra para acesso a Curitiba com estes resíduos. Além disso, como medida para atingir o pequeno gerador, é primordial o uso de campanhas pelas prefeituras e a criação de pontos de entrega voluntária, garantindo a coleta dos RCC gerados e dando um destino mais nobre aos mesmos.

\section{Declaração de conflito de interesses}

Os autores declaram não haver conflitos de interesses.

\section{Referências}

Abrelpe - Associação Brasileira de Empresas de Limpeza Pública e Resíduos Especiais. Panorama dos resíduos sólidos no Brasil 2014. 2014. Disponível em: <http://www.abrelpe.org.br/Panorama/ panorama2014.pdf $>$. Acesso em: 18 nov. 2015.

Angulo, R. J. (Coord.). Diagnóstico do Município de Pontal do Paraná, subsídio para a elaboração do plano diretor. Curitiba: FUNPAR, 1999. v. 1.

Angulo, S. C.; John, V. M. Normalização dos agregados graúdos de resíduos de construção e demolição reciclados para concretos e a variabilidade. Anais do IX Encontro Nacional de Tecnologia do Ambiente Construído, Foz do Iguaçu, 2002. Disponível em: <http://www.infohab.org.br/ entac2014/2002/Artigos/ENTAC2002_1613 _1624.pdf>. Acesso em: 16 nov. 2015.

Angulo, S. C.; Ulsen, C.; John, V. M.; Kahn, H. Desenvolvimento de novos mercados para a reciclagem massiva de RCD. Anais do $\mathbf{V}$ Seminário de Desenvolvimento Sustentável e a Reciclagem na Construção Civil, São Paulo, p. 293-307, 2002.
Bigarella, J. J. Matinho: homem e terra, reminiscências... 3. ed. ampl. Curitiba: Fundação Cultural de Curitiba, 2009.

Brasil. Leis, decretos, etc. Lei $\mathbf{n}^{0}$ 12.305, de 2 de agosto de 2010. Institui a Política Nacional de Resíduos Sólidos; altera a Lei $n^{\circ}$ 9.605, de 12 de fevereiro de 1998; e dá outras providências. Disponível em: <http://www.planalto.gov.br/ccivil_03/ _ato2007-2010/2010/lei/l12305.htm>.

Acesso em: 16 nov. 2015.

Brasil. Leis, decretos, etc. Resolução CONAMA n ${ }^{\circ}$ 307, de 5 de julho de 2002. Estabelece diretrizes, critérios e procedimentos para a gestão dos resíduos da construção civil. Disponível em: $<$ http://www.mma.gov.br/port/conama/ legiabre.cfm?codlegi=307> . Acesso em: 16 de novembro de 2015.

Brasil. Leis, decretos, etc. Resolução CONAMA n ${ }^{\circ} 348$, de 16 de agosto de 2004. Altera a Resolução CONAMA $n^{\circ}$ 307 , de 5 de julho de 2002, incluindo o amianto na classe de resíduos perigosos. Disponível em: <http://www.mma.gov.br/ port/conama/legiabre.cfm?codlegi=449>.

Acesso em: 16 nov. 2015.

Brasil. Leis, decretos, etc. Resolução CONAMA n ${ }^{\circ}$ 431, de 24 de maio de 2011. Altera 0 art. $3^{\circ}$ da Resolução $n^{\circ} 307$, de 5 de julho de 2002, do Conselho Nacional do Meio Ambiente-CONAMA, estabelecendo nova classificação para o gesso. Disponível em: <http://www.mma.gov.br/port/conama/ legiabre.cfm?codlegi=649> . Acesso em: 16 nov 2015.

Brasil. Leis, decretos, etc. Resolução CONAMA $n^{\circ}$ 448, de 19 de janeiro de 2012. Altera os arts. $2^{\circ}, 4^{\circ}, 5^{\circ}, 6^{\circ}, 8^{\circ}, 9^{\circ}, 10$ e 11 da Resolução $n^{\circ}$ 307, de 5 de julho de 2002, do Conselho Nacional do Meio Ambiente-CONAMA. Disponível em: $<$ http://www.mma.gov.br/port/conama/ legiabre.cfm?codlegi=672> . Acesso em: 16 nov. 2015.

Colit - Conselho do Litoral. Plano Diretor de Desenvolvimento Integrado de Pontal do Paraná. Caderno Diagnóstico. 2004. Disponível em: <http://www.colit.pr.gov.br/ modules/conteudo/conteudo.php?conteudo= 11>. Acesso em: 09 jun. 2009. 
Colit - Conselho do Litoral. Plano Diretor Participativo e de Desenvolvimento Integrado de Matinhos. Diagnóstico Municipal Socioeconômico e Fisicoterritorial. (Caderno 1). 2006. Disponível em: <http://www.colit.pr.gov.br/ arquivos/ File/caderno_1de2.pdf $>$. Acesso em: 16 nov. 2015.

Deschamps, M. V.; Kleinke, M. L. U. Os fluxos migratórios e as mudanças socioespaciais na ocupação contínua litorânea do Paraná. Revista Paranaense de Desenvolvimento, n. 99, p. 45-59. 2000.

Deschamps, M. V.; Kleinke, M. L. U.; Moura, R.; Werneck, D. Z. Afinal, o que induz o crescimento nas aglomerações litorâneas? Anais do XII Encontro de Estudos Populacionais da ABEP, Caxambu, 2000. Disponível em: $<$ http://www.abep.nepo.unicamp.br/docs/ anais/pdf/2000/Todos/migt4_2.pdf $>$.

Acesso em: 16 nov. 2015.

IBGE. Instituto Brasileiro de Geografia e Estatística. Resultados preliminares do censo 2010. Rio de Janeiro: IBGE, 2010. Disponível em: <http://www.ibge.gov.br/ home/estatistica/populacao/censo2010/ resultados_preliminares_amostra/notas_ resultados_preliminares_amostra.pdf $>$. Acesso em: 15 nov. 2010.

John, V. M.; Agopyan, N. Reciclagem de resíduos da construção. Artigo. São Paulo: PCC-EPUSP. Disponível em: $<$ http//www.reciclagem.pcc.usp.br $>$. Acesso em: 15 jul. 2005.

Marques Neto, J. C. Gestão dos resíduos de construção e demolição no Brasil. 1. ed. São Carlos: Rima, 2005.

Matinhos. Leis, Decretos, etc. Decreto $\mathbf{n}^{\circ}$ 381, de 07 de dezembro de 2006. Regulamenta a coleta de entulhos proveniente de demolições, restos de construções, material vegetal decorrente de podas ou cortes. Disponível em: $<$ https://leismunicipais.com.br/a/pr/m/ matinhos/decreto/2006/38/381/decreto-n381-2006-regulamenta-a-coleta-deentulhos-proveniente-de-demolicoes-restosde-construcoes-material-vegetal-decorrentede-podas-ou-cortes $>$. Acesso em: 16 nov. 2015.
Miranda, L. F. R. Estudo de fatores que influem na fissuração de revestimentos de argamassa com entulho reciclado. São Paulo: Universidade de São Paulo, Escola Politécnica, 2000. (Dissertação de Mestrado).

MMA - Ministério do Meio Ambiente. Projeto de Gestão Integrada da Orla Marítima - Projeto Orla: Plano de Intervenção na Orla Marítima de Matinhos. Brasília: MMA, 2004a. Disponível em: $<$ http://www.colit.pr.gov.br/arquivos/File/ Projeto_Orla/Matinhos.pdf > . Acesso em: 05 out. 2015.

MMA - Ministério do Meio Ambiente. Projeto de Gestão Integrada da Orla Marítima - Projeto Orla: Plano de Intervenção na Orla Marítima de Pontal do Paraná. Brasília: MMA, 2004b. Disponível em: <http://www.colit.pr.gov.br/arquivos/ File/Projeto_Orla/PontalPR.pdf $>$. Acesso em: 05 out. 2015.

Morais, G. M. D. Diagnóstico da disposição clandestina de resíduos da construção e demolição em bairros periféricos de Uberlândia: subsídios para uma gestão sustentável. Uberlândia: Universidade Federal de Uberlândia, 2006. (Dissertação de mestrado).

Paraná. Leis, decretos, etc. Decreto $\mathbf{n}^{\mathbf{0}}$ 2.722, de 14 de março de $\mathbf{1 9 8 4}$. Aprova 0 regulamento que especifica e define as condições para o aproveitamento de áreas e locais considerados de interesse turístico, de que trata o artigo $1^{\circ}$ da Lei Estadual $n^{\circ}$ 7.389, de 12 de novembro de 1980 . Disponível em: <http://www.colit.pr.gov.br/ arquivos/File/Legislacao/Decreto_2722_14 _marco_1984.pdf $>$. Acesso em: 26 out. 2015.

Pierri, N. O litoral do Paraná: entre a riqueza natural e a pobreza social. Desenvolvimento e Meio Ambiente, n. 8, p. 25-41, 2003.

Pierri, N.; Angulo, R. J.; Souza, M. C.; Kim, M. K. A. Ocupação e o uso do solo no litoral paranaense: condicionantes, conflitos e tendências. Desenvolvimento e Meio Ambiente, n. 13, p. 137-167, 2006.

Pinto, T. P. Metodologia para a gestão diferenciada de resíduos sólidos da 
construção urbana. São Paulo: Universidade de São Paulo, Escola Politécnica, 1999. (Tese de doutorado).

Pinto, T. P.; González, J. L. R. (Coord.). Manejo e gestão de resíduos da construção civil: manual de orientação: Brasília, Caixa, 2005. (v. 1; Como implantar um Sistema de Manejo e Gestão nos Municípios). Disponível em: $<$ http://www.cuiaba.mt.gov.br/upload/ arquivo/Manual_RCD_Vol1.pdf $>$. Acesso em: 05 out. 2015.

Pontal do Paraná. Leis, decretos, etc. Lei Complementar $n^{0}$ 004, de 3 de agosto de 2007. Dispõe sobre a utilização dos logradouros públicos no município de Pontal de Paraná, o bem-estar, a ordem, os costumes e a segurança pública, estabelece normas de proteção e conservação do meio ambiente, observadas as normas federais e estaduais relativas às matérias. Disponível em: <http://www.pontaldoparana.pr.gov.br/ portalnovo/index.php/municipio/legislacaomunicipal/leis-municipais/leis-

complementares/Leis Municipais/Leis Complementares/LC n004 - Código de Posturas.pdf/download>. Acesso em: 26 out. 2015.

Pontal do Paraná. Leis, decretos, etc. Lei $\mathbf{n}^{\circ}$ 303, de 8 de janeiro de 2002. Dispõe sobre a regularização de edificações irregulares e dá outras providências. Disponível em: $<$ http://www.pontaldoparana.pr.gov.br/wpcontent/uploads/2015/07/Lei303-Dispõesobre-a-regularização-de-edificaçõesirregulares.pdf > . Acesso em: 05 out. 2015.
Pontal do Paraná. Prefeitura de Pontal do Paraná. Plano de Gestão Integrada de Resíduos Sólidos Urbanos do Município de Pontal do Paraná-PR. Pontal do Paraná: Prefeitura Municipal de Pontal do Paraná, 2008. Disponível em: $<$ http://site.pontaldoparana.pr.gov.br/pdf/ proposicoes.pdf $>$. Acesso em: 05 out. 2015. Schneider, D. M. Deposições irregulares de resíduos da construção civil na Cidade de São Paulo. São Paulo: Universidade de São Paulo, Departamento de Saúde Ambiental, 2003. (Dissertação de mestrado).

Schneider, D. M.; Philippi Jr., A. Gestão pública de resíduos da construção civil no Município de São Paulo. Ambiente Construído, v. 4, n. 4, p. 21-32, 2004.

Sinduscom. Resíduos da construção civil e o Estado de São Paulo. 2012. Disponível em: <http://www.ambiente.sp.gov.br/?s= resíduos+da+construção+civil>. Acesso em: 18 nov. 2015.

Souza, U. E. L.; Paliari, J. C.; Agopyan, V.; Andrade, A. C. Diagnóstico e combate à geração de resíduos na produção de obras de construção de edifícios: uma abordagem progressiva. Ambiente Construído, v. 4, n. 4, p. 33-46, 2004.

Zordan, S. E. A utilização do entulho como agregado, na confeç̧ão do concreto. Campinas: Universidade Estadual de Campinas, Faculdade de Engenharia Civil, 1997. (Dissertação de mestrado).

Informação da Licença: Este é um artigo Open Access distribuído sob os termos da Licença Creative Commons Attribution, que permite uso irrestrito, distribuição e reprodução em qualquer meio, desde que a obra original seja devidamente citada. 